\title{
Almeida Garrett e o cânone romântico
}

Regina Zilberman 
J oão B atista da Silva L eitão de Almeida Garrett nasceu no Porto, em 1799, filho de Antônio Bernardo da Silva, funcionário superior das Alfândegas; adotou o sobrenome G arrett, que pertencia à sua avó paterna, de origem irlandesa. Passou a infância nos Açores, onde a família se refugiou durante a invasão francesa, em 1809; em 1816, foi para Coimbra, diplomando-se em Direito, em 1820. No mesmo ano, mudou-se para L isboa, vindo a trabalhar na Secretaria dos Negócios do R eino. Em 1823, fugiu para a Inglaterra, em virtude do restabelecimento do absolutismo em Portugal; retornou em 1826, com a outorgação da Carta Constitucional por D. Pedro IV; mas, em 1828, partiu para novo exílio na Inglaterra, com a ascensão de D. M iguel. Em 1832, com Alexandre Herculano e outros, juntou-se aos liberais que, do exílio, desembarcaram no M indelo, tomando parte no cerco do Porto. Logo depois, foi nomeado cônsul em Bruxelas, retornando a Portugal em 1836, data a partir da qual intensificou sua atividade política de recorte liberal. Em 1851, foi nomeado Visconde, em 1852, M inistro dos N egócios Estrangeiros, função de que se demitiu no ano seguinte. Faleceu em 9 de dezembro de 1854, em Lisboa.

Sua obra é bastante vasta, e seu papel, na literatura portuguesa do século XIX, fundamental: introduziu a estética romântica naquele país, inaugurada pelos livros de poemas Camões, de 1825, e D. Branca, de 1826. Publicou a primeira obra em 1821: Retrato de Vênus; a última, Folhas caídas, em 1853. Entre as duas datas, apareceram, entre outras, Catão (1822), Adozinda (1828), Lírica de J oão 
Mínimo (1829) , Da Educação (1829), Portugal na Balança da Europa (1830), Um Auto de Gil Vicente (1841), O Alfageme de Santarém (1842), Frei Luís de Sousa (1844), Flores sem Fruto (1845), O Arco de Sant'Ana (1845-850), Filipa de Vilhena (1846), Viagens na Minha Terra (1846), A Sobrinha do Marquês (1848).

A organização do Parnaso Lusitano, ou “Poesias Seletas dos Autores Portugueses Antigos e M od ernos, I lustradas com N otas", data de 1826, coincidindo com a publicação das obras que abriam Portugal à estética romântica. P recede a coletânea o "Bosquejo da História da Poesia e Língua Portuguesa", anunciada, na folha de rosto do primeiro volume da antologia, como "H istória Abreviada da Língua e Poesia Portuguesa"; na página VII, contudo, quando se inicia o ensaio, ele traz o título pelo qual passou a ser conhecido. O Parnaso lusitano, aparentemente a primeira seleta em língua portuguesa e modelo das subseqüentes organizadas no Brasil, como as de J anuário da Cunha Barbosa, de $1829,{ }^{1}$ e de J . M. Pereira da Silva, de 1843, foi publicado em seis volumes por J.P. Aillaud, casa editora situada em Paris. O primeiro volume, com o ensaio de Almeida G arrett, apareceu em 1826, os demais em $1827^{2}$.

A participação de Almeida Garrett na feitura do livro é controversa. Ele mesmo, a propósito do plano geral da obra, faz o seguinte comentário, em nota contida no "Ao L eitor" que introduz seu ensaio sobre educação, de 1828:

J á em outra parte protestei que nada meu tinha no Parnaso Lusitano que publicou o Sr. Aillaud, livreiro em Paris, senão o resumo da história literária de Portugal que vem no princípio do primeiro tomo daquela coleção. É certo que arranjei o sistema e plano da obra, que escolhi os autores e peças; mas ausentando-me de Paris antes de completa a impressão do primeiro volume, um homem por nome Fonseca, a quem de minha algibeira paguei para rever as provas, tomou a liberdade de alterar tudo, introduzindo na coleção produções ridículas de gente desconhecida, e que eu nunca vira, omitindo muitas das que eu escolhera, enxovalhando tudo com notas pueris e indecentes, errando vergonhosamente até o índice de matérias que eu preparara para cada volume, e introduzindo uma ortografia galega que faz rir a gente e que está em contradição com as regras que eu na prefação estabelecera (...). - R epito esta declaração para que me não atribuam as grossas tolices e grossas má criações que emporcalham aquela obra, que tão bela podia ser. (p. 673)

Vale destacar que em nenhum dos tomos, nem na folha de rosto, no "Bosquejo" ou no "A Quem Ler", que o precede, aparece o nome de Almeida Garrett; contudo, no tratado sobre educação, ele afirma que segue "nesta obra as mesmas

1. Cf. Antonio Candido, Formação da Literatura Brasileira (Momentos decisivos), 2. ed. revista, São Paulo, Martins, 1964, v. 2, p. 320.

2. Teófilo Braga ( 1905) indica que o último volume teria sido publicado em 1834. Cf. Teófilo B raga, Garrett e os Dramas Românticos, Porto, Lello \& Irmão, 1905. 
regras que para a do PAR NASO LUSITANO tinha estabelecido", (p. 673) atestando indiretamente a autoria da coletânea e, por extensão, do ensaio de história da literatura com que a abre. Por isso, Teófilo Braga, organizador da obra completa de Almeida G arrett, observa que “o plano geral é de G arrett, embora alterado por J osé da Fonseca"; Braga indica também o teor dos seis volumes, divididos conforme o gênero literário a que os poemas selecionados pertencem, e anota que o último tomo, compreendendo os satíricos, não teria sido feito por Garrett.

Vitor R amos, (1972) pesquisador das publicações portuguesas realizadas na F rança entre 1800 e 1850, comenta, por seu turno:

Garrett publicou em Paris o Camões e a D. Branca, e escreveu o Bosquejo de introdução ao volume do Parnaso Lusi tano, organizado por J osé da Fonseca. Mais tarde, bem instalado na vida, realizado política e artisticamente, Garrett nega ter tido qualquer parte na escolha dos poetas que figuram no Parnaso e condena em termos duros o trabalho feito pelo pobre Fonseca. Não vai ao ponto de negar a autoria do Bosquejo. (p. 36)

O único texto assinado é o da dedicatória, na primeira página: dirigida à Sereníssima Senhora D ona I sabel Maria³, R egente do R eino, J oão Pedro Aillaud, que a subscreve, diz: "A promessa lisonjeira com que Vossa Alteza Real deu nova esperança e vida às Artes Portuguesas já quase extintas por tantos séculos de desfavor e desgraça, me animou a ajuntar nesta coleção o mais precioso da Poesia Nacional, e dedicá-la a Vossa Alteza Real, como primícias dos abundantes frutos que de tão criador amparo hão de brotar." No parágrafo subseqüente, o editor encerra: "Aos pés de Vossa Alteza R eal se prostra com profundo respeito,/ O mais humilde e leal vassalo", a que se segue a assinatura, "J oão Pedro Aillaud", e a data: "Paris, 30 de agosto, 1826."

Após a dedicatória e antes do "Bosquejo", um "A Quem Ler", entre as páginas I a VI, resume os objetivos e os critérios do organizador. Essa apresentação nem sempre é reproduzida integralmente nas edições posteriores do ensaio, ficando restrita ao parágrafo final, colocado, como faz Teófilo B raga, por exemplo, na edição da Obra Completa de AImei da Garrett, como introdução ao "B osquejo", entre o título e o início do capítulo I, sobre "Origem de Nossa Língua e Poesia".

O parágrafo de encerramento do "A Quem Ler" é, sem dúvida, essencial à compreensão do "Bosquejo", pois, ali, G arrett esclarece as intenções que o levaram a produzir o texto:

- o desejo de encetar a história da literatura portuguesa, narrada na perspectiva nacional, e não examinada por um estrangeiro;

3. Filha de D. J oão VI e D. Carlota J oaquina, I sabel M aria foi regente de 1826, ano da morte de seu pai, até 1828, quando entregou o cargo a D. Miguel, seu irmão. 
- a necessidade de corrigir os erros de informação e interpretação encontráveis nas obras que B outerwek ${ }^{4}$, e Sismondi ${ }^{5}$, anteriores à sua pesquisa.

Eis as palavras do crítico:

J ulgo haver prestado algum serviço à literatura nacional em oferecer aos estudiosos de sua língua e poesia um rápido bosquejo da história de ambas. Quem sabe que tive de encetar matéria nova, que português nenhum dela escreveu, e os dois estrangeiros B outerwek e Sismondi incorretíssimamente e de tal modo que mais confundem do que ajudam a conceber e ajuizar da história literária de Portugal; avaliará decerto o grande e quase indizível trabalho que me custou esse ensaio. Não quero dá-lo por cabal e perfeito; mas é o primeiro, não podia sê-lo. Além de que, a maior parte das idéias vão apenas tocadas, porque não havia espaço em obra de tais limites para Ihe dar o necessário desenvolvimento.

O "B osquejo da História da Poesia e Língua Portuguesa" ocupa as páginas VII a LXXVII do primeiro volume, seguindo-Ihe a coletânea. Os tomos estão divididos conforme os gêneros literários, sendo o primeiro dedicado à poesia épica, o segundo, aos poemas descritivos e didáticos bucólicos e herói-cômicos, o terceiro, aos epigramáticos e líricos, o quarto, também à poesia lírica, destacando-se os sonetos, os epigramas, as odes, os ditirambos e as elegias, o quinto à poesia dramática (tragédia e comédia). No último tomo, dos satíricos, aparece O Hissope, poema herói-cômico de Antônio Dinis da Cruz e Silva. ${ }^{6}$

Abreu, Antônio Dinis da Cruz e Silva, Antônio Ferreira, Antônio Lopes de Veiga, Antônio R ibeiro dos Santos, B elchior M anuel Curvo Semedo Torres Sequeira, B ento Luís Viana, B ernardim R ibeiro, D. Leonor de Almeida ( M arquesa de Alorna), Diogo Bernardes, Domingos dos Reis Quita, Domingos Maximiano Torres, Fernão Álvares do Oriente, Francisco de B orja G arção Stockler, F rancisco de Sá de M iranda, Francisco J osé Freire, Francisco Manuel do Nascimento, Francisco Manuel Gomes da Silveira Malhão, Francisco Rodrigues Lobo, Francisco Sá de Meneses, Frei J osé do Coração de J esus, Gabriel Pereira de Castro, J erônimo Corte-R eal, J oão Batista Gomes, J oão Evangelista de M oraes Sarmento, J oão Vicente Pimentel M aldonado, J oão Xavier de Matos, J osé Agostinho de Macedo, J osé Anastácio da Cunha, J osé Xavier Valadares e Sousa, Luís da Silva M ouzinho de Albuquerque, Luís de Camões, Luís Pereira Brandão, Manuel Maria Barbosa du Bocage, Manuel Matias, Miguel do

4. F riedrich B outerwek (1765-1828) escreveu a História da Poesia e da Eloqüência Portuguesa, obra publicada em 1805

5. J ean-Charles-Léonard Simonde de Sismondi (1773-1842) publicou De la Littérature du Midi del'Europe em 1813, em quatro volumes; no último deles, ocupa-se da literatura portuguesa.

6. Antônio Dinis da Cruz e Silva (1731-1799), fundador da Arcádia L usitana, escreveu o poema herói-cômico O Hissope, que satiriza questões da Igreja em Portugal. Foi também o juiz enviado por Portugal ao Brasil, para julgar os réus Cláudio M anuel da Costa, Tomás Antônio Gonzaga e Alvarenga Peixoto, acusados de conspirar contra a administração lusitana. 
Couto Guerreiro, Nicolau Tolentino, Paulino Antônio Cabral de Vasconcelos, Pedro Antônio J oaquim Correia Garção, Pero de Andrade Caminha, Tomás Antônio dos Santos Silva, Vasco Quevedo de Quevedo Castelo Branco e Vicente Pedro Nolasco da Cunha - estes são, em ordem alfabética, os autores dos poemas selecionados.

Também se encontram os seguintes brasileiros, com seus respectivos poemas: no volume I, B asílio da G ama ( "Lindóia”, de O Uraguai) e Santa R ita Durão ("M oema", de Caramuru); no volume II , F rancisco de M elo F ranco ("A estupidez triunfante em Coimbra", de O reino da estupidez); no volume III, Cláudio Manuel da Costa ( "N ise! Nise! onde estás? Aonde espera", "B reves horas, A mor, há que eu gozava"); nos volumes III e IV, Borges de Barros ("A flor saudade", "À noite", "À virtude"), J osé B onifácio de Andrada ("Os fachos pelos ares sacudindo", "Adeus, fica-te em paz Alcina amada", "A criação da mulher", "A poesia”, “À amizade") e Tomás Antônio Gonzaga ( “O contentamento", “O perjúrio”, “O retrato”, “Todos amam" e "R ecordações"); no volume V, Paulo J osé de M elo ( "O círio", epístola). O Padre Sousa Cald as comparece no volume II, com "As aves", no volume IV, com os salmos "Beatus vir qui non abiit" e "Quare fremuerunt gentes" e as odes "A existência de Deus", "O homem selvagem" e “Pigmalião", bem como no volume V, com "Carta a J oão de Deus Pires Ferreira".

No "B osquejo", contudo, Almeida Garrett não se refere a todos esses poetas, avaliando a obra de Antônio J osé da Silva, o J udeu (que, sendo dramaturgo, não poderia estar presente numa coletânea de poemas), Basílio da Gama, Cláudio Manuel da Costa, Santa Rita Durão, Sousa Caldas e Tomás Antônio Gonzaga. O exame desses autores dá-se no contexto geral da literatura portuguesa, dividida em períodos históricos, conforme o quadro abaixo:

Seqüência

Primeira época literária

Segunda época literária

Terceira época literária

Quarta época literária

Quinta época literária

Época (sic)
Período de tempo

J ulgamento

Fins do séc. XIII até os princípios do XVI

Desde os princípios do séc. XVI até os do XVII

Começo até o fim do séc. XVII

Fins do séc. XVII, até meados do séc. XVIII

M eios do séc. XVIII, até o fim
Idade de ouro da poesia e da língua

Principia a corromper-se o gosto e a declinar a língua

Idade de ferro; aniquila-se a literatura, corrompe-se inteiramente a língua

R estauração das letras em Portugal

Segunda decadência da língua e literatura; galicismo e traduções 
Como se verifica, Almeida G arrett

- organiza os fatos literários segundo uma linha de tempo, e não conforme os gêneros literários, modo como aparecem os textos no interior da seleta;

- ordena o fluxo temporal em termos de "elevação" e "queda", evitando a linha continuamente ascendente na direção do progresso; sua avaliação do presente é desalentadora, embora deixe no ar a expectativa de novos e bons tempos:

A literatura portuguesa não mostra presentemente grandes sintomas de vigor: mas há muita força latente sob essa aparência; o menor sopro animador que da administração Ihe venha, ateará muitos luzeiros com que de novo brilhe e se engrandeça.

- esse recorte cronológico leva em conta um critério externo - os séculos ou meio-séculos em seqúência; outro critério externo, mas não meramente cronológico, decorre da relação entre os períodos literários e a atuação de personalidades da política portuguesa, como D. J oão I, D. Manuel e o Marquês de Pombal;

- o recorte também leva em conta um critério interno, pois, dentro de cada época, o historiador procura características literárias dominantes, sendo as mais salientes o emprego da língua (portuguesa ou espanhola, sendo o primeiro fator julgado positivo, e o segundo negativo) e a influência de determinados autores: Gôngora e Marino, no século XVII, Bocage na passagem do século XVIII para o $X I X$, influências estas tidas como nefastas;

- ainda que examine a linguagem poética desde a terminologia da retórica, Almeida G arrett entende a língua como elemento definidor da nacionalidade, sendo o escrever em português valor estético que recomenda as obras; some-se a essa visão lingüística a rejeição das influências e da imitação, e ter-se-á a sintonia do autor com os pressupostos da estética romântica.

Este aparece igualmente quando se examina o principal critério de análise e crítica dos autores, que, para ele, é a constatação, nas obras, a presença ou falta do "espírito nacional". E mbora o nativismo ou a cor local sejam conceitos semeados e difundidos pelo R omantismo, a começar por Madame de Staël, princípios que, em tese, deveriam contar exclusivamente para a produção do período, G arrett vale-se dele para examinar e legitimar a produção do passado. Assim, condena a maior parte dos escritores do século XVI português por faltar neles a representação da natureza local e imediata:

O Tejo, o Mondego, os montes, os sítios conhecidos de nosso país e dos que nos deu a conquista, figuram em seus poemas; porém raro se vê descrição que recorde algum desses sítios que já vimos, que nos lembre os costumes, as usanças, os preconceitos mesmos populares; que daí vem à poesia o aspecto e feições nacionais, que são sua maior beleza. 
Ou:

Com elas todas medrou e cresceu a poesia na delicadeza, na harmonia, no gosto; porém desmereceu muito, demasiado na originalidade, no caráter próprio, que perdeu quase todo, na nacionalidade, que por mui pouco se lhe ia. Todos os deuses gregos tomaram posse do maravilhoso poético, todas as imagens, todas as idéias; todas as alusões do tempo de Augusto ocuparam as mais partes da poesia; e mui pouco ficou para o que era nacional, para o que já tínhamos, para o que podíamos adquirir ainda, para o que naturalmente devia nascer de nossos usos, de nossas recordações, de nossa arqueologia, do aspecto de nosso país, de nossas crenças populares, e enfim de nossa religião.

Ou:

O público preferia (e com razão também) o com que fora criado, o que o interessava, o que o divertia, e antes queria rir com as grosserias dos autos populares, que bocejar e adormecer-se com as finuras da arte e correções dessas comédias, que tudo tinham, menos interesse, onde todo o espírito havia, menos o nacional.

Se houveram Sá de M iranda e Ferreira escolhido assuntos portugueses, se houveram pintado os costumes nacionais, e apresentado ao público, em vez de quadros italianos, um espelho em que se ele visse a si e aos seus usos, e se risse de seus próprios defeitos; fico em que houveram reformado o teatro em vez de lhe empecer (...) .

É conforme o mesmo critério que faz a crítica aos brasileiros do século XVIII:

E agora começa a literatura portuguesa a avultar e enriquecer-se com as produções dos engenhos brasileiros. Certo é que as majestosas e novas cenas da natureza naquela vasta região deviam ter dado a seus poetas mais originalidade, mais diferentes imagens, expressões e estilo, do que neles aparece: a educação européia apagou-Ihes o espírito nacional: parece que receiam de se mostrar americanos; e daí lhes vem uma afetação e impropriedade que dá quebra em suas melhores qualidades.

\section{Por essa razão condena G onzaga:}

Gonzaga, mais conhecido pelo nome pastoril de Dirceu, e pela sua M arília, cuja beleza e amores tão célebres fez naquelas nomeadas liras. (...) Se houvesse por minha parte de Ihe fazer alguma censura, só me queixaria, não do que fez, mas do que deixou de fazer. Explico-me: quisera eu que em vez de nos debuxar no Brasil cenas da Arcádia, quadros inteiramente europeus, pintasse os seus painéis com as cores do país onde os situou. Oh! e quanto não perdeu a poesia nesse fatal erro! se essa amável, se essa ingênua M arília fosse, como a Virgínia de Saint-Pierre, sentar-se à sombra das palmeiras, e enquanto lhe revoavam em torno o cardeal soberbo com a púrpura dos reis, o sabiá terno e melodioso, - que saltas- 
se pelos montes espessos a cotia fugaz como a lebre da E uropa, ou grave passeasse pela orla da ribeira o tatu escamoso, - ela se entretivesse em tecer para o seu amigo e seu cantor uma grinalda não de rosas, não de jasmins, porém dos roxos martírios, das alvas flores dos vermelhos bagos do lustroso cafezeiro; que pintura, se a desenhara com sua natural graça o ingênuo pincel de Gonzaga!

\section{E valoriza Basílio da Gama:}

J usto elogio merece o sensível cantor da infeliz Lindóia que mais nacional foi que nenhum de seus compatriotas brasileiros. O Uraguai de J osé B asílio da $\mathrm{G}$ ama é o moderno poema que mais mérito tem na minha opinião. Cenas naturais mui bem pintadas, de grande e bela execução descritiva; frase pura e sem afetação, versos naturais sem ser prosaicos, e quando cumpre sublimes sem ser guindados; não são qualidades comuns. Os brasileiros principalmente lhe devem a melhor coroa de sua poesia, que nele é verdadeiramente nacional, e legítima americana.

\section{O mesmo critério leva-o a condenar as traduções:}

Mas de traduções estamos nós gafos: e com traduções levou o último golpe a literatura portuguesa; foi a estocada de morte que nos jogaram os estrangeiros. Traduzir livros de artes, de ciências é necessário, é indispensável; obras de gosto, de engenho, raras vezes convêm; é quase impossível fazê-lo bem, é míngua e não riqueza para a literatura nacional. Essa casta de obras estuda-se, imita-se, não se traduz. Quem assim faz acomoda-as ao caráter nacional, dá-Ihes cor de próprias, e não só veste um corpo estrangeiro de alfaias nacionais (como o tradutor), mas a esse corpo dá feições, gestos, modo, e índole nacional: assim fizeram os latinos, que sempre imitaram os gregos e nunca os traduziram; assim fizeram os nossos poetas da boa idade. Se Virgílio houvera traduzido a llíada, Camões a Enei da, Tasso Os Lusíadas, Milton a J erusalém, K lopstock o Paraíso perdido; nenhum deles fora tamanho poeta, nenhuma dessas línguas se enriquecera com tão preciosos monumentos: e todavia imitaram uns dos outros, e dessa imitação Ihes veio grande proveito.

\section{Bem como a aconselhar um poeta de seu tempo:}

Eu por mim tomarei a confiança de pedir ao ilustre poeta, em nome da literatura portuguesa, que na segunda edição de sua tão útil obra não desdenhe de aproveitar os muitos e riquíssimos ornatos que habilmente pode tirar de nossas festas rurais, de nossas usanças (como feiras, serões, desfolhas, etc.), das descrições de nosso formoso país; com que decerto fará mais nacional e interessante seu estimável poema.

Este elenco de idéias, empregadas para avaliar a literatura portuguesa produzida entre o final da I dade M édia e o começo do século XIX, revela o fundamen- 
to romântico da estética de Almeida G arrett, a mesma que semeava em Portugal com os poemas citados, Camões, de 1825, e D. Branca, de 1826. O crítico mostrava-se coerente com o poeta, enquanto apresentava a arte de seu tempo como superior. Por conseqüência, Almeida G arrett não apenas fundou a história da literatura em língua portuguesa; ele igualmente formulou os valores que vão presidir a criação e avaliação de obras artísticas, especialmente poéticas, entre os escritores de seu tempo, inclusive os brasileiros.

É nesse sentido que se pode afirmar que, entre nós, de um lado, a história da literatura brasileira, de que Almeida Garrett é um dos patronos, nasce ao mesmo tempo que seu objeto, pois a literatura do Brasil só pôde receber essa denominação após a separação de Portugal; de outro, que essa historiografia, aplicada à literatura brasileira, não era apenas retrospectiva, mas também prospectiva, apresentando aos poetas e intelectuais de seu tempo normas e princípios que deveriam acatar, para seus escritos terem valor estético. Dentre esses valores, o da tradução da cor local foi dos que mais pesou, expresso por Almeida G arrett e repetido por seus seguidores, como J oaquim Norberto, Pereira da Silva e Francisco Adolfo de Varnhagen, nos ensaios que esses escreverem entre 1840 e $1850 .^{7}$

Nem mesmo M achado de Assis ficou imune às palavras de Garrett, como se lê em seu estudo de 1858, "O Passado, o Presente e o Futuro da Literatura", onde escreve:

Gonzaga, um dos mais líricos poetas da língua portuguesa, pintava cenas da Arcádia, na frase de G arrett, em vez de dar uma cor local às suas liras, em vez de dar-Ihes um cunho puramente nacional.

Também sua avaliação de O Uraguai, de Basílio da Gama, é mediada pelo juízo do crítico português:

Para contrabalançar, porém, esse fato cujos resultados podiam ser funestos, como uma valiosa exceção apareceu o Uruguai ( $\mathrm{sic}$ ) de Basílio da Gama. Sem trilhar a senda seguida pelos outros, Gama escreveu um poema, se não puramente nacional, ao menos nada europeu.

Como Garrett, o jovem Machado rejeita a tradução, prejudicial, no caso, ao desenvolvimento do teatro nacional:

7. Cf. a respeito R egina Zilberman, A fundação da literatura brasileira, in Revista de Literatura Comparada. (1994), e Regina Zilberman, A Terra em que Nasceste, Imagens do B rasil na Literatura, 1994. 
Para que estas traduções enervando a nossa cena dramática? Para que esta inundação de peças francesas, sem o mérito da localidade e cheias de equívocos, sensaborões às vezes, e galicismos, a fazer recuar o mais denodado francelho?

Quando escreve seu conhecido ensaio "I nstinto de Nacionalidade", publicado em 1873, M achado ainda está dialogando com A Imeida G arrett, revisando avaliações manifestadas no estudo anterior, como a que atinge Gonzaga. Assim, depois de reconhecer que, "quem examina a atual literatura brasileira reconheceIhe logo, como primeiro traço, certo instinto de nacionalidade", comenta, como se antes não tivesse também compartilhado a mesma opinião:

Sente-se aquele instinto até nas manifestações da opinião, aliás mal formada ainda, restrita em extremo, pouco solícita, e ainda menos apaixonada nestas questões de poesia e literatura. Há nela um instinto que leva a aplaudir principalmente as obras que trazem os toques nacionais. A juventude literária, sobretudo, faz deste ponto uma questão de legítimo amor-próprio. Nem toda ela terá meditado os poemas de Uruguai (sic) e Caramuru com aquela atenção que tais obras estão pedindo; mas os nomes de Basílio da Gama e Durão são citados e amados, como precursores da poesia brasileira. A razão é que eles buscaram em roda de si os elementos de uma poesia nova, e deram os primeiros traços de nossa fisionomia literária, enquanto que outros, G onzaga por exemplo, respirando aliás os ares da pátria, não souberam desligar-se das faixas da Arcádia nem dos preceitos do tempo. Admira-se-Ihes o talento, mas não se lhes perdoa o cajado e a pastora, e nisto há mais erro que acerto.

Contestando o argumento de G arrett, M achado está questionand o o cânone romântico dominante, na forma que o crítico e poeta português o propôs, quase cinqüenta anos antes. Durante as cinco décadas que separam um e outro ensaio, consolidou-se a estética fundada na noção de cor local, até o esgotamento que o anteriormente partidário dela Machado de Assis diagnosticou. 


\section{Referências bibliográficas}

GARRETT, Almeida. Ao leitor. In Da educação. Obras de Almeida Garrett. Porto: Lello \& Irmão, 1966.

. A quem ler. In Parnaso lusitano. Paris: J. P. Ailland, 1826.

. Bosquejo da história da poesia e língua portuguesa. In Parnaso lusitano. Paris: J .

P. Ailland, 1826.

ASSIS, Machado de. O passado, o presente e o futuro da literatura. In COUTINHO, A frânio (org.). Obra completa. Rio de J aneiro: Aguilar, 1958, v. III. . Instinto de nacionalidade. In Crítica literária. São Paulo: Mérito, 1959.

BRAG A, Teófilo. Garrett e os dramas românticas. Porto: Lello \& Irmão, 1905.

RAMOS, Vitor. A edição portuguesa em França (1800-1850). Repertório geral dos títulos publicados e ensaio crítico. Paris: Fundação Calouste Gulbenkian, Centro Cultural português, 1972.

ZILBERMAN, R egina. A fundação da literatura brasileira. In Revista brasileira de literatura comparada. São Paulo: Abralic, (2): 59-68, maio 1994.

. A terra em que nasceste, I magens do Brasi I na literatura. Porto Alegre: E ditora da UFRGS, 1994. 